\title{
Ultra-trace Arsenic Determination in Urine and Whole Blood Samples by Flow Injection-Hydride Generation Atomic Absorption Spectrometry after Preconcentration and Speciation Based on Dispersive Liquid-Liquid Microextraction
}

\author{
Hamid Shirkhanloo, ${ }^{\dagger, \star}$ Ahmad Rouhollahi, ${ }^{\dagger, *}$ and Hassan Zavvar Mousavi ${ }^{\S}$ \\ ${ }^{\dagger}$ Department of Chemistry, Faculty of Science, K. N. Toosi University of Technology, Tehran, Iran \\ ${ }^{*}$ E-mail: rouhollahi@kntu.ac.ir \\ ${ }^{\star}$ Research of Petroleum Industry Health Organization, Medical Industrial Laboratory, Tehran, Iran \\ ${ }^{\S}$ Department of Chemistry, College of Science, Semnan University, Semnan, Iran \\ Received February 3, 2011, Accepted August 6, 2011
}

\begin{abstract}
A noble method for pre-concentration and speciation of ultra trace As (III) and As (V) in urine and whole blood samples based on dispersive liquid-liquid microextraction (DLLME) has been developed. In this method, As (III) was complexed with ammonium pyrrolidine dithiocarbamate at $\mathrm{pH}=4$ and Then, As (III) was extracted into the ionic liquid (IL). Finally, As (III) was back-extracted from the IL with hydrochloric acid (HCl) and its concentration was determined by flow injection coupled with hydride generation atomic absorption spectrometry (FI-HGAAS). Total amount of arsenic was determined by reducing As (V) to As (III) with potassium iodide (KI) and ascorbic acid in $\mathrm{HCl}$ solution and then, $\mathrm{As}(\mathrm{V})$ was calculated by the subtracting the total arsenic and As (III) content. Under the optimum conditions, for 5-15 mL of blood and urine samples, the detection limit $(3 \sigma)$ and linear range were achieved $5 \mathrm{ng} \mathrm{L}^{-1}$ and $0.02-10 \mu \mathrm{g} \mathrm{L}^{-1}$, respectively. The method was applied successfully to the speciation and determination of As (III) and As (V) in biological samples of multiple sclerosis patients with suitable precision results $(\mathrm{RSD}<5 \%)$. Validation of the methodology was performed by the standard reference material (CRM).
\end{abstract}

Key Words : Arsenic, Speciation, Ionic liquid, Dispersive liquid-liquid microextraction, FI-HGAAS

\section{Introduction}

Exposure to arsenic occurs mostly in the workplace, near hazardous waste sites, or in areas with high natural levels. Arsenic (As) has two forms (inorganic and organic) in human body. Inorganic arsenic compounds react with sulfhydryl (-SH) groups of cellular proteins and are toxic in human body but organic arsenic is usually less harmful. ${ }^{1-3}$ therefore, speciation and determination of inorganic arsenic in urine and whole blood samples, especially in multiple sclerosis patients is very important. ${ }^{4,5}$ The toxicity of arsenic compounds is generally linked to the soluble inorganic trivalent forms (arsenite), which is controlled by $\mathrm{pH}$. Arsenic can be very toxic to the central nervous system (CNS) and thus, in some cases, may play a significant role in multiple sclerosis patients (MS). Human exposure assessment to arsenic containing substances includes short term (recent or acute exposure) and long term (chronic exposure) tests that can be performed to monitor detoxification efficiencies. Chronic or acute exposure of arsenic can lead to progressive peripheral and central nervous changes, such as, numbness and muscle tenderness. Other symptoms of arsenic poisoning may include headaches, diarrhea, vomiting, confusion and cancer. ${ }^{3}$ Monitoring the arsenic concentration in urine, accompanied by blood tests provide short term supportive evidence of exposure and detoxification. The urine and blood test is the most reliable test for arsenic exposure within the last few days. Long term exposure of arsenic can be identified by analysis of epithelial tissue such as hair and skin. Tests on hair and fingernails can measure exposure of arsenic over the past 612 months. Normal arsenic concentrations in blood and urine are typically below $50 \mu \mathrm{g} \mathrm{L}^{-1}$ and $7 \mu \mathrm{g} \mathrm{L}^{-1}$, respectively. ${ }^{6-8}$ For determination and speciation of ultra trace concentrations of As in urine and whole blood samples an extraction procedure is necessary to get arsenic species in solution before analysis. Also, it requires sensitive analytical techniques such as; ion chromatography-inductively coupled plasma-mass spectrometry (IC-ICP-MS), high performance liquid chromatography coupled to inductively coupled plasma mass spectrometry (HPLC-ICP-MS), ${ }^{9-11}$ coprecipitation, ${ }^{12}$ inductively coupled plasma atomic emission spectrometry (ICP-AES), ${ }^{13}$ HPLC coupled to inductively coupled plasma mass spectrometry, ${ }^{14}$ hydride generation atomic absorption spectrometry (HGAAS) ${ }^{15,16}$ hydride generation and atomic fluorescence spectrometry (HGAFS), ${ }^{17,18}$ electrothermal atomic absorption spectrometry (ETAAS) ${ }^{19}$ and chemiluminescence method ${ }^{20}$ have been recommended for the purpose. Among them, HGAAS is probably the most common technique used for low level concentrations of As in biological samples, due to its high sensitivity, speed of analysis and minimum sample preparation. But in order to achieve accurate, sensitive and reliable results at ultra trace levels of $\mathrm{As}(\mathrm{III})$ and $\mathrm{As}(\mathrm{V})$ with HG-AAS, pre-concentrate ion and separation steps are required prior to analyte determination. A number of procedures involving by liquid-liquid extraction, ${ }^{21}$ anodic stripping voltametry, ${ }^{22}$ hydride gene- 
ration atomic fluorescence spectrometry, ${ }^{23,24}$ energy-dispersive $\mathrm{X}$ ray fluorescence and solid phase extraction ${ }^{25}$ have been used for the determination of the low concentration levels of arsenic. Recently, DLLME has been developed and attracted increasing attention for its high enrichment factor and high extraction efficiency.

The aim of this study is the use of DLLME combined with FI-HGAAS to develop a new procedure for the speciation and determination of ultra-trace amount of As (III) and As (V). APDC is used as a chelating agent to extract As (III) into the ionic liquid (IL) at $\mathrm{pH}=4 .^{26}$ The fact that $\mathrm{As}$ (V) does not react with APDC $\left(\mathrm{As}^{5+}<5 \%\right)$ allows the speciation of the inorganic trivalent and pentavalent forms of Arsenic. ${ }^{27}$ Multiple sclerosis patients were chosen for determination trivalent (III) and pentavalent (V) forms of inorganic arsenic in urine and blood samples. The method was applied successfully to speciation and determination of As (III) and As (V) by FI-HGAAS.

\section{Experimental}

Apparatus. The experiments were performed using an atomic absorption spectrometer equipped with a FI-HGAAS (GBC-932, 3000, AUS). A hollow cathode lamp operated at a current of $8 \mathrm{~mA}$ and a wavelength of $193.7 \mathrm{~nm}$ with a spectral band width of $1 \mathrm{~nm}$ and deuterium background corrector was applied. All containers (quartz crucibles, plastic tubes) were cleaned with detergent and treated successively by the hydrochloric acid and rinsed with de-ionized water. The pure argon gas (99.99\%) was used as a carrier gas for HGAAS analysis and the $\mathrm{pH}$ values of the solutions were measured by a digital $\mathrm{pH}$ meter (Metrohm 744).

Reagents. All chemicals of analytical grade such as nitric acid, hydrochloric acid, APDC, Polyoxyethylene octyl phenyl ether (TX-100), sodium acetate, sodium hydroxide, and sodium borohydride $\left(\mathrm{NaBH}_{4}\right)$ were from Merck Germany. Reducing agents (aqueous solution of $0.6 \%$ sodium borohydride in $0.5 \%$ sodium hydroxide) were prepared freshly and filtered before use. Arsenic standard solutions were prepared from a stock solution of $1000 \mathrm{mg} \mathrm{L}^{-1}$ as ultra trace in 2\% nitric acid from Fluka Switzerland (No; 39436). Working standard solutions were prepared by dilution of stock and intermediate standards. KI and IL (1-butyl-3methylimidazolium hexafluorophosphate) were purchased from Sigma Alderich. Buffer solutions were prepared from 1-2 $\mathrm{mol} \mathrm{L}^{-1}$ sodium acetate and acetic acid for $\mathrm{pH} \mathrm{3-7} \mathrm{and}$ from $0.2 \mathrm{~mol} \mathrm{~L}^{-1}$ ammonium chloride and ammonia for $\mathrm{pH}$ 8-10. Ultrapure water was obtained from a Water System of Iranian research Institute of Petroleum Industry (Millipore, RIPI).

Sampling. For sampling procedure, all the glass tubes were cleaned by $2 \mathrm{~mol} \mathrm{~L}^{-1}$ nitric acid. Arsenic concentrations in whole blood and urine are very low. Thus, even minor contamination at any sampling, sample storage and handling or analytical stage has the potential to affect the accuracy of the results. $20 \mathrm{~mL}$ of whole blood and $50 \mathrm{~mL}$ of urine samples were collected from department of multiple sclerosis from Esfahan, Iran. Urine samples were collected in a plastic container with $0.35 \mathrm{~mL}$ of concentrated $\mathrm{HCl}$. Whole blood samples were collected in heparinize tubes and were stored at $4^{\circ} \mathrm{C}$.

General Procedure. Dispersive liquid-liquid microextraction has been developed as a new mode of liquid phase microextraction and attracted increasing attention for its simple operation, high enrichment factor, rapidity and high extraction efficiency. In this technique, a ternary component solvent system: two organic solvents having different characteristics are involved in use, one is hydrophilic which performs as dispersive solvent such as aceton $\mathrm{e}^{28}$ and the other is hydrophobic which performs as extraction solvent such as carbon tetrachloride. ${ }^{29}$ In this work, $1 \mathrm{~mL}$ of $1 \%(\mathrm{w} / \mathrm{v})$ APDC solution was added to $15 \mathrm{~mL}$ of blood and urine samples and $\mathrm{pH}$ was adjusted to 4 with buffer solution in a centrifuge tube. Then, $0.2 \mathrm{~g}$ of IL was added to the mixtures and they were shaken with a vortex apparatus for $2 \mathrm{~min}$. Arsenic (III) was complexed and pre-concentrated as AsAPDC in IL. The phases were separated by centrifuging of turbid solution at 3 min with $3500 \mathrm{rpm}$. Removing procedures involving nitric acid should be avoided as this acid tend to produce higher oxidation states of the analyte elements (As (V)), which are generally unfavorable for the hydride generation process. Also, $\mathrm{NO}_{\mathrm{x}}$ compounds produced during nitric acid removing can interfere with the $\mathrm{NaBH}_{4}$ as a reduction reaction and reduce the analytical sensitivity. So, for removing the aqueous phase, $0.5 \mathrm{~mL}$ of 2 mol L $\mathrm{L}^{-1}$ hydrochloric acid solution was added and the mixture was shaken for $1 \mathrm{~min}$ and then, was diluted with $1 \mathrm{~mL}$ of ultrapure water. Finally, the resulting solution determined by FI-HGAAS.

After As (V) was reduced to As (III) with $1 \mathrm{~mol} \mathrm{~L}^{-1}$ of KI and ascorbic acid, ${ }^{30}$ the total arsenic was determined. In addition, the concentration of As (V) was calculated by subtracting the content of As (III) from total arsenic content.

\section{Results and Discussion}

Instrumental Conditions for FI-HG-AAS. Absorbtion $(\mathrm{S} / \mathrm{N})$ and repeatability of the results were investigated for the speciation and determination As (III) and As (V) in urine and blood samples by flow injection coupled with hydride generation atomic absorption spectrometer (FI-HGAAS). The mixed solution flows through a reaction coil where the metal hydride is formed and then into a gas-liquid separator where the hydride vapour is removed from the bulk liquid using an inert carrier gas (Argon 99.99\%). The hydride is then fed into a fused quartz absorption cell which is mounted over a burner and heated by an air-acetylene flame. Flame conditions of hydride cell were with $1.2 \mathrm{~L} \mathrm{~min}^{-1}$ fuel and minimum flow air. The instrumental conditions are listed in Table 1. Working range was between 0.03-3.4 $\mu \mathrm{g} \mathrm{L} \mathrm{L}^{-1}$ for 15 $\mathrm{mL}$ samples at peak area (Figure 1).

Effect of pH Range. APDC was used to improve affinity and chelation of the arsenic in ionic liquids phase. The complexation phenomenon is strongly conditioned by the 
Table 1. The instrumental parameters and extraction conditions of proposed method for analysis of arsenic

\begin{tabular}{lc}
\hline Features & Value \\
\hline Precision (\%RSD, N=10) & 3.2 \\
LOD of DLLME & $0.005 \mu \mathrm{g} \mathrm{L}^{-1}$ \\
Linear range of DLLME, PA $(15 \mathrm{~mL})$ & $0.03-3.4 \mu \mathrm{g} \mathrm{L}^{-1}$ \\
Linear range of DLLME, PA $(5 \mathrm{~mL})$ & $0.1-10 \mu \mathrm{g} \mathrm{L}^{-1}$ \\
Correlation coefficient of DLLME & $\mathrm{R}=0.9965$ \\
\hline Linear range of FI-HGAAS (PA) & $0.5-30 \mu \mathrm{g} \mathrm{L}^{-1}$ \\
Linear range of FI-HGAAS (PH) & $2-9.8 \mu \mathrm{g} \mathrm{L}^{-1}$ \\
Correlation coefficient of FI-HGAAS & $\mathrm{R}=0.9987$ \\
Wavelength & $197.2 \mathrm{~nm}$ \\
Spectral band width & $1 \mathrm{~nm}$ \\
Lamp current & $8 \mathrm{~mA}$ \\
\hline
\end{tabular}

PA $=$ Peak Area, $\mathrm{PH}=$ Peak Height

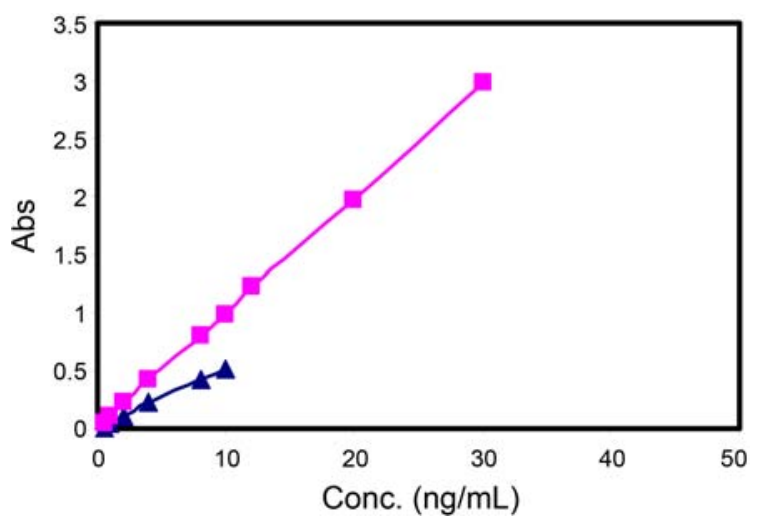

Figure 1. Working range of As (III) by FI-HGAAS at peak hight (A) and area (ם); wavelength: $197.2 \mathrm{~nm}$.

$\mathrm{pH}$ of solutions and subsequently affects the extraction efficiency of the As-APDC complex. Therefore, the effect of $\mathrm{pH}$ was studied in the $\mathrm{pH}$ range of 1-12. The results show that the highest extraction efficiency for As (III) was achieved in $\mathrm{pH}=4$ but $\mathrm{As}(\mathrm{V})$ does not react with APDC (AsV $<5 \%$ ). So the procedure was applied to speciation of the inorganic trivalent and pentavalent forms arsenic (Figure 2).

Effect of APDC Concentration. It is very important to establish the minimal reagent concentration that leads to total complex formation while achieving the highest extraction. The concentration of APDC was increased until the total extraction of As (III) was obtained. The extraction efficiency was stable when the APDC concentration was higher than $10 \times 10^{-6} \mathrm{~mol} \mathrm{~L}^{-1}$. Therefore, the concentration of $12 \times 10^{-6} \mathrm{~mol} \mathrm{~L}^{-1}$ APDC was selected for $15 \mathrm{~mL}$ of samples (Figure 3).

Optimization of Amount of IL and Extraction Time. The variation of extraction efficiency upon IL amount was examined within the range of 0.05-0.2 g. It was observed that the extraction efficiency of the system was remarkably affected by the IL amount. Quantitative extraction was observed for (BMIM $\mathrm{PF}_{6}$ ) higher than $0.18 \mathrm{~g}$ for $15 \mathrm{~mL}$ samples. Therefore, in order to achieve a suitable preconcentration, $0.2 \mathrm{~g}$ IL was chosen as optimum leading to a final IL (Figure 4). The effectiveness of As extraction under

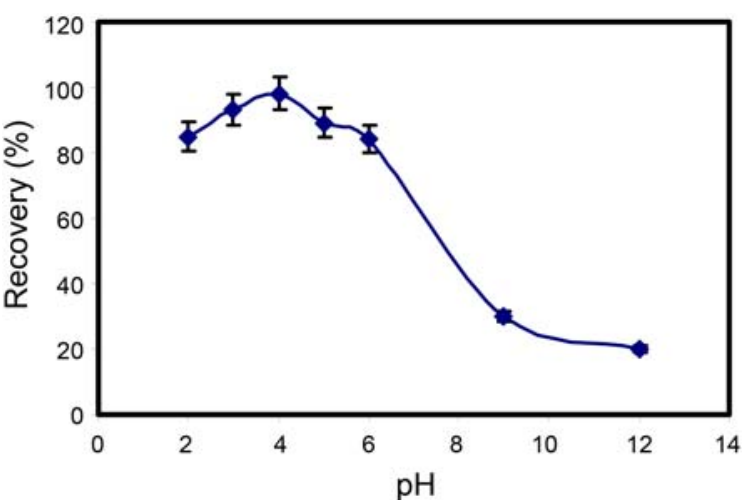

Figure 2. The influence of samples $\mathrm{pH}$ on the recovery ( $\mathbf{\square})$ Concentration of As (III): $200 \mathrm{ng} \mathrm{L}^{-1}$; amount of ionic liquid: $0.2 \mathrm{~g}$; extraction time: $7 \mathrm{~min}$; sample volume: $15 \mathrm{~mL} ; \mathrm{N}=3 ; \mathrm{pH}=4.0$.

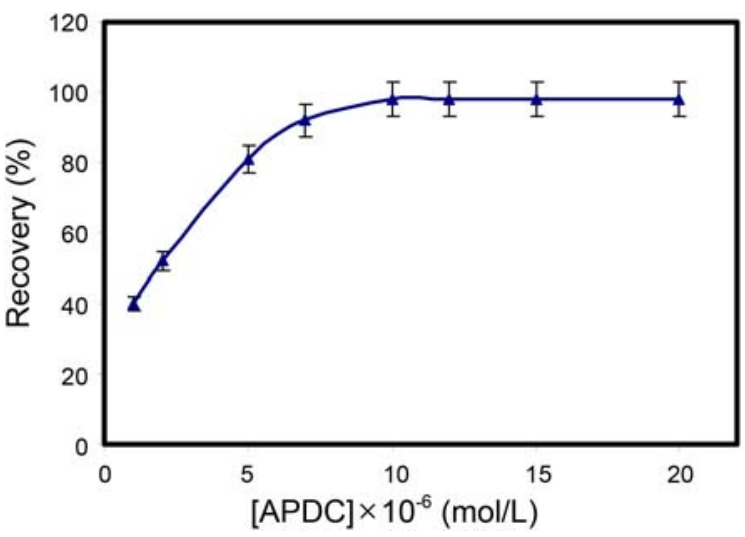

Figure 3. The influence of APDC concentration on the recovery (A). Concentration of As (III): $200 \mathrm{ng} \mathrm{L}^{-1}$; amount of ionic liquid: $0.2 \mathrm{~g}$; extraction time: $7 \mathrm{~min} ; \mathrm{pH}=4.0$; Concentration APDC: 12 mol L ${ }^{-1} \times 10^{-6}$; centrifugation rate: $3500 \mathrm{rpm}$; sample volume: 15 $\mathrm{mL} ; \mathrm{N}=3$.

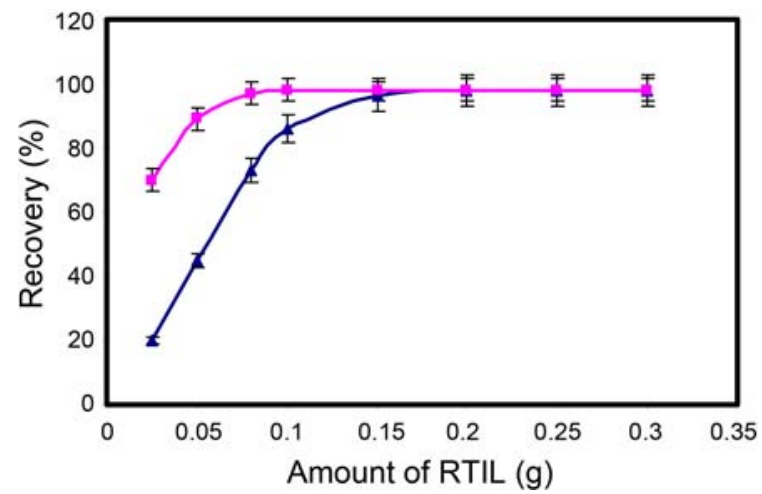

Figure 4. The influence of amount of ionic liquid $\left(\mathrm{BMIM} \mathrm{PF}_{6}\right)$ on the recovery. Concentration of As (III): $200 \mathrm{ng} \mathrm{L}^{-1}$; amount of ionic liquid: $0.2 \mathrm{~g}$; $\mathrm{pH}=4.0$; valume of sample: $5 \mathrm{~mL}(\boldsymbol{\square}): 15 \mathrm{~mL}(\boldsymbol{\Delta})$.

the influence of shaking and centrifugation time was also studied and optimized. Two minute shaking and three minute centrifuging $(3500 \mathrm{rpm})$ were selected as optimum time, since complete separation occurred and no noticeable improvements on analyte extraction were observed for longer periods of time.

Effect of Sample Volume. Sample volume is one of the 


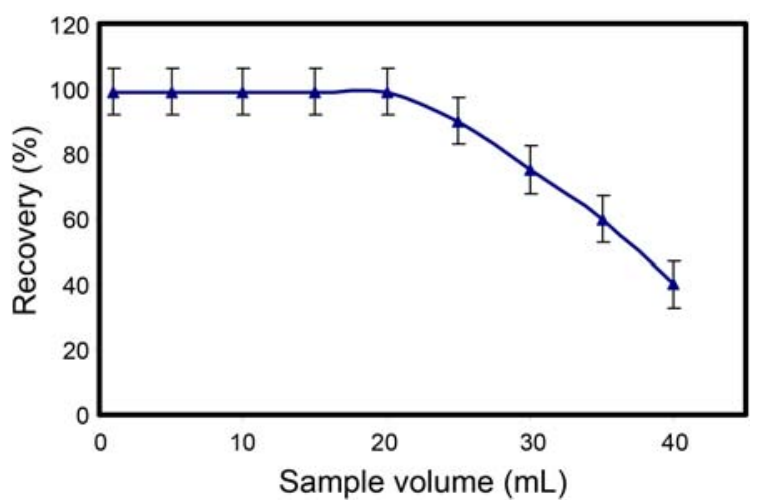

Figure 5. The influence of sample volume on the recovery $(\mathbf{A})$. Concentration of As (III): $200 \mathrm{ng} \mathrm{L}^{-1}$; amount of ionic liquid: $0.2 \mathrm{~g}$; extraction time: $7 \mathrm{~min}$; $\mathrm{pH}=4.0$; sample volume: $15 \mathrm{~mL}$.

most important parameter to be studied when real samples are analyzed by a pre-concentration technique, since it conditions the sensitivity enhancement of the method. The effect of sample volume was examined in a range of 1-50 $\mathrm{mL}$ for $200 \mathrm{ng} \mathrm{L}^{-1}$ As. It was found that the analyte could be recovered quantitatively up to $20 \mathrm{~mL}$ of the sample and the recoveries were decreased at higher volume. It was also noticed as the sample volume gets higher it is partially solubilized in IL phase, therefore leading to non-reproducible results. For this purpose, $15 \mathrm{~mL}$ of the sample volume was selected for further experiments and the enrichment factor (EF) 10 was achieved (Figure 5).

Table 2. Method validation for determinations of arsenic by standard reference material

\begin{tabular}{ccccc}
\hline SRM & $\begin{array}{c}\text { Certified } \\
\text { value As (III) } \\
\mu g \text { L}^{-1}\end{array}$ & $\begin{array}{c}\text { Certified } \\
\text { value As (V) } \\
\mu g \mathrm{~L}^{-1}\end{array}$ & $\begin{array}{c}\text { Found }^{b} \\
\text { As (III) } \\
\mu \mathrm{g} \mathrm{L}^{-1}\end{array}$ & $\begin{array}{c}\text { Found }^{b} \\
\mathrm{As}(\mathrm{V}) \\
\mu \mathrm{g} \mathrm{L}\end{array}$ \\
\hline urine $^{a}$ & $2.50 \pm 0.20$ & $1.50 \pm 0.20$ & $2.46 \pm 0.16$ & $1.44 \pm 0.09$ \\
\hline
\end{tabular}

${ }^{a}$ NIST SRM 2670 , Arsenic in frozen dried urine, $\mathrm{pH} 4.0,-20{ }^{\circ} \mathrm{C} .{ }^{b}$ Mean of three determinations \pm confidence interval $(\mathrm{P}=0.95)$
Interferences Study. Generally, ammonium pyrrolidine dithiocarbamate is a chelating agent for many transition metals. Thus, interferences from coexisting ions should be considered. The effect of potential interferes occurring in blood and urine samples on the determination of arsenic were tested using the optimized preconcentration system. The recovery of $200 \mathrm{ng} \mathrm{L}^{-1}$ of arsenic was tested with individual interferences added. Taking as criterion for interference the deviation of the recovery more than $\pm 5 \%$, the obtained results showed that many ions such as $\mathrm{Cd}^{2+}, \mathrm{Cu}^{2+}, \mathrm{Zn}^{2+}, \mathrm{Ni}^{2+}$, $\mathrm{Co}^{2+}, \mathrm{Mn}^{2+}, \mathrm{Pb}^{2+}$ and $\mathrm{V}^{3+}$ could be tolerated up to at least 2

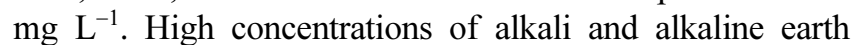
metals, $\mathrm{CO}_{3}{ }^{2-}$ and $\mathrm{PO}_{4}{ }^{3-}$ which are usually found in urine and blood samples, were tested. Ions such as, $\mathrm{K}^{+}, \mathrm{Na}^{+}, \mathrm{CO}_{3}{ }^{2-}$, $\mathrm{PO}_{4}{ }^{3-}, \mathrm{Ca}^{2+}$ and $\mathrm{Mg}^{2+}$ up to $3 \mathrm{mg} \mathrm{L}{ }^{-1}$ did not cause any interference.

Method Validation. In order to show the validity of this method, for analysis samples with DLLME method, $15 \mathrm{~mL}$ of blood and urine samples were used. Results showed that there are no interferences from major consistent of blood and urine samples and interferences of transition metal ions; therefore we have explored the feasibility of the methodo-

Table 4. The capability of different methods for determination of As (III), As (V) and total arsenic in human samples $(\mathrm{N}=3$, $\mathrm{P}=0.95)$

\begin{tabular}{ccccc}
\hline \multirow{2}{*}{ Methods } & \multirow{2}{*}{ ETAAS } & $\begin{array}{c}\text { DLLME }+ \\
\text { FI-HG-AAS }\end{array}$ & FI-HG-AAS \\
\hline \multirow{3}{*}{ Blood } & As (V) & - & $0.112 \pm 0.008$ & $-^{a}$ \\
& As (III) & - & $0.134 \pm 0.021$ & - \\
& Total & ND & $0.246 \pm 0.032$ & ND $^{b}$ \\
\hline \multirow{5}{*}{ Serum } & As (V) & - & $0.413 \pm 0.062$ & - \\
& As (III) & - & $0.526 \pm 0.093$ & - \\
& Total & ND & $0.939 \pm 0.161$ & $1.074 \pm 0.032$ \\
\hline Hair & Total & $5.221 \pm 0.187$ & $4.967 \pm 0.328$ & $5.314 \pm 0.258$ \\
Nail & Total & ND & $0.151 \pm 0.011$ & ND \\
\hline$a^{a}$ Unm & & & &
\end{tabular}

${ }^{a}$ Unmeasurable. ${ }^{b}$ Not Detected

Table 3. Speciation and determination of As (III) and As (V) in spiked real samples by proposed method

\begin{tabular}{|c|c|c|c|c|c|c|c|}
\hline \multirow{2}{*}{ Sample } & \multicolumn{2}{|c|}{$\operatorname{Added}^{a}\left(\mu \mathrm{g} \mathrm{L}^{-1}\right)$} & \multicolumn{2}{|c|}{ Found $^{a}\left(\mu \mathrm{g} \mathrm{L}^{-1}\right)$} & \multirow{2}{*}{ Total } & \multicolumn{2}{|c|}{ Recovery (\%) } \\
\hline & As (III) & As $(V)$ & As (III) & As (V) & & As (III) & As (V) \\
\hline \multirow[t]{3}{*}{ WB } & - & - & $0.107 \pm 0.012$ & $0.242 \pm 0.031$ & $0.349 \pm 0.051$ & - & - \\
\hline & 0.1 & - & $0.211 \pm 0.016$ & $0.237 \pm 0.024$ & $0.448 \pm 0.037$ & 102 & 98 \\
\hline & - & 0.2 & $0.103 \pm 0.007$ & $0.439 \pm 0.033$ & $0.542 \pm 0.062$ & 96 & 99 \\
\hline \multirow[t]{3}{*}{ Urine } & - & - & $0.421 \pm 0.034$ & $0.292 \pm 0.043$ & $0.713 \pm 0.085$ & - & - \\
\hline & 0.5 & - & $0.892 \pm 0.104$ & $0.311 \pm 0.026$ & $1.203 \pm 0.128$ & 97 & 107 \\
\hline & - & 0.5 & $0.414 \pm 0.068$ & $0.782 \pm 0.091$ & $1.196 \pm 0.142$ & 98 & 99 \\
\hline \multirow[t]{3}{*}{ WB } & - & - & $0.193 \pm 0.025$ & $0.098 \pm 0.005$ & $0.291 \pm 0.062$ & - & - \\
\hline & 0.2 & - & $0.389 \pm 0.072$ & $0.101 \pm 0.003$ & $0.490 \pm 0.062$ & 99 & 103 \\
\hline & - & 0.1 & $0.189 \pm 0.007$ & $0.192 \pm 0.013$ & $0.381 \pm 0.042$ & 98 & 97 \\
\hline \multirow[t]{3}{*}{ Serum } & - & - & $0.252 \pm 0.024$ & $0.233 \pm 0.033$ & $0.485 \pm 0.066$ & - & - \\
\hline & 0.1 & - & $0.354 \pm 0.056$ & $0.229 \pm 0.037$ & $0.583 \pm 0.073$ & 101 & 98 \\
\hline & - & 0.2 & $0.245 \pm 0.017$ & $0.435 \pm 0.063$ & $0.680 \pm 0.094$ & 97 & 100 \\
\hline \multirow[t]{3}{*}{$\mathrm{WB}^{b}$} & - & - & $3.242 \pm 0.116$ & $4.134 \pm 0.213$ & $7.376 \pm 0.265$ & - & - \\
\hline & 1 & - & $4.119 \pm 0.252$ & $4.067 \pm 0.174$ & $8.186 \pm 0.331$ & 97 & 98 \\
\hline & - & 2 & $3.191 \pm 0.207$ & $6.088 \pm 0.323$ & $9.279 \pm 0.536$ & 98 & 99 \\
\hline
\end{tabular}

${ }^{a}$ Mean of three determinations \pm Confidence interval $(\mathrm{P}=0.95) .{ }^{b}$ Whole Blood $(5 \mathrm{~mL})$ 
Table 5. Comparison of the published methods with the proposed method in this work

\begin{tabular}{|c|c|c|c|c|c|}
\hline Method & Separation method & Linear range $\left(\mu \mathrm{g} \mathrm{L}^{-1}\right)$ & Detection limit $\left(\mu \mathrm{g} \mathrm{L}^{-1}\right)$ & RSD $\%$ & Reference \\
\hline ICP-MS & $\mathrm{SPE}^{b}$ & $0.02-5.0$ & 0.008 & 1.1 & [31] \\
\hline HGAAS & Coprecipitation & - & 0.012 & 8.0 & [32] \\
\hline ETAAS & $\mathrm{SFDME}^{d}$ & $0.10-0.7$ & 0.0092 & 8.6 & [33] \\
\hline ETAAS & $\operatorname{DLLME}^{c}$ & $0.06-2.0$ & $0.01,0.036$ & 3.2 & {$[34,35]$} \\
\hline ETAAS & $\mathrm{CPE}^{a}$ & $0.10-20$ & 0.04 & 3.1 & {$[36]$} \\
\hline FI-HGAAS & DLLME $^{c}$ & $0.03-3.4^{e}$ & 0.005 & 3.2 & This work \\
\hline
\end{tabular}

${ }^{a}$ Cloud Point Extraction. ${ }^{b}$ Solid Phase Extraction. ${ }^{c}$ Dispersive Liquid- Liquid Micro Extraction. ${ }^{d}$ Solidification of Floating Drop Microextraction. ${ }^{e}$ As mentioned in Table 1, linear range for $5 \mathrm{~mL}$ samples is up to $10 \mu \mathrm{g} \mathrm{L}^{-1}$.

logy using proposed method for the determination of arsenic ions in different matrices. Validation of the methodology was performed by standard reference material (NIST SRM 2670) with certified values for As (V) and As (III). The results are shown in Table 2. Also, the spiked urine, serum and human blood were prepared to demonstrate the reliability of the method for determination of As (III) and As (V). The results for this study are presented in Table 3. Different methods indicate the capability of the system in the determination of As (III), As (V) and total arsenic in real samples, which is shown in Table 4 and 5.

\section{Conclusion}

This procedure takes the advantage of the combination of a very simple and reliable way of pre-concentrating blood and urine samples for arsenic determination and speciation with the sensitive FI-HGAAS technique. The increase in sensitivity resulting from sample preconcentration and speciation of the trivalent and pentavalent inorganic forms of these analytes, makes the procedure can be considered as an alternative to ion chromatography coupled to inductively coupled plasma mass spectrometry (IC-ICPMS). The detection limits based on three times the standard deviation of the blank $(N=10)$ was $0.005 \mu \mathrm{g} \mathrm{L}^{-1}$. The results showed quantitative extraction (96\%) and suitable precision results (RSD $<5 \%$ ). Working range was between 0.03-3.4 $\mu \mathrm{g} \mathrm{L}^{-1}$ for $15 \mathrm{~mL}$ samples at peak area. In this procedure, satisfactory results of ultra trace analysis of arsenic species in blood and urine samples of multiple sclerosis patients (MS) were obtained. The results of this study showed that the proposed method is accurate, precise and time efficient, as just a very simple sample treatment is required.

Acknowledgments. The authors thank from Petroleum Industry Health Organization (PIHO), Medical Industrial Laboratory of PIHO and Research Institute of Petroleum Industry (IRPI), Tehran, Iran.

\section{Referenecs}

1. Hughes, M. F. J. Toxicol. Lett. 2002, 133, 1.

2. Sounderajan, S.; Udas, A. C.; Venkataraman, B. J. Hazard. Mater. 2007, 149, 238 .

3. Arsenic, Agency for Toxic Substances and Disease Registry (ATSDR), January, 2006.
4. Templeton, D. M.; Ariese, F.; Cornelis, R.; Danielsson, L.; Muntau, H.; Van Leeuwen, H. P.; Lobinski, R. J. Pure. Appl. Chem. 2000, 72, 1453.

5. Tongesayi, T.; Smart, R. B. J. Environ. Chem. 2006, 3, 137.

6. Barnett, M. H.; Prineas, J. W. J. Ann. Neurol. 2004, 55, 458.

7. Kachev, D.; Mimmack, M. L.; Huffaker, S. J.; Ryan, M.; Bahn, S. Int. J. Neuropsychopharmacol. 2007, 10, 557.

8. Stenehjem, A. E.; Vahter, M.; Nermell, B.; Aasen, J.; Morland, J. J. Clinic. Toxic. 2007, 45, 424.

9. Nam, S.; Oh, H.; Min, H.; Lee, J. Microchem J. 2010, 95, 20.

10. Kuenstl, L.; Griesel, S.; Prange, A.; Goessler, W. J. Environ. Chem. 2009, 6, 319.

11. Dobran, S.; Zagury, G. J. Sci. Total Environ. 2006, 364, 239.

12. Elçi, L.; Divrikli, U.; Soylak, M. Int. J. Environ. Anal. Chem. 2008, 88, 711 .

13. Koh, J.; Kwon, Y.; Pak, Y. Microchem J. 2005, 80, 195.

14. Rodriguez, I. B.; Raber, G.; Goessler, W. Food Chem. J. 2009, 112,1084

15. Kumar, A. R.; Riyazuddin, P. Int J. Environ. An. Ch. 2008, 88, 255.

16. Bundaleska, J. M.; Stafilov, T.; Arpadjan, S. Int. J. Environ. An. Ch. 2005, 85, 199.

17. El-Hadri, F.; Morales-Rubio, A.; Guardia, M. Food Chem. J. 2007, 105, 1195.

18. Ojeda, C. B.; Rojas, F. S.; Pavón, J. M. C. Anal. Bioanal. Chem. $\mathbf{2 0 0 5}, 382,513$.

19. Serafimovski, I.; Karadjova, I. B.; Stafilov, T.; Tsalev, D. L. Microchem J. 2006, 83, 55.

20. Kumar, A. R.; Riyazuddin, P. Int. J. Environ. An. Ch. 2007, 87, 469.

21. Dugo, G.; La Pera, L.; Turco, V. Lo.; Di Bella, G. J.Chemosphere 2005, 61, 1093.

22. Zih-Perenyi, K.; Jankovics, P.; Sugar, E.; Lasztity, A. J. Spectrochim Acta 2008, 63, 445.

23. Correia, C. L. T.; Gonçalves, R. A.; Azevedo, M. S.; Vieira, M. A.; Campos, R.C. Microchem J. 2010, 96, 157.

24. Sun, Y. C.; Yang, J. Y. Anal. Chim. Acta 1999, 395, 293.

25. Zhang, L.; Morita, Y.; Sakuragawa, A.; Isozaki, A. Talanta 2007, 72,723 .

26. Komjarova, I.; Blust, R. Anal. Chim. Acta 2006, 576, 221.

27. Anezaki, K.; Nukatsuka, L.; Ohzeki, K. Anal. Sci. J. 1999, 5, 829.

28. Farahani, H.; Norouzi, P.; Dinarvand, R.; Ganjali, M. R. J. Chromatogr. A 2007, 1172, 105.

29. Birjandi, A. P.; Bidari, A.; Rezaei, F.; Hosseini, M. R. M.; Assadi, Y. J. Chromatogr. A 2008, 1193, 19.

30. Kowalska, J.; Stryjewska, E.; Szymánski, P.; Golimowski, J. Electroanalysis 1999, 11, 1301.

31. Chunhai, Y.; Qiantao, C.; Zhong, G.; Zhaoguang, Y.; Soo, B. K. Spectrochimica Acta Part B 2003, 58, 1335.

32. Tuzen, M.; Citak, D.; Soylak, M. Talanta 2009, 78, 52.

33. Mahnaz, G.; Mohammad, R. K. Z.; Yadollah, Y.; Ali, E.; Najmeh, Y. Talanta 2010, 81, 197.

34. Ricardo, E. R.; Ignacio, L. G.; Manuel, H. C. Spectrochimica Acta Part B 2009, 64, 329.

35. Pei, L.; Lili, P.; Ping, Y. Microchim Acta 2009, 166, 47.

36. An-na, T.; Guo-sheng, D.; Xiu-ping, Y. Talanta 2005, 67, 942. 